\title{
Caregiver's characteristics of Alzheimer's disease patient and risk of depression in southern Tunisia
}

\section{Ghanmi ${ }^{1}$, D Farhat ${ }^{1}$, M Abbes ${ }^{1}$, M Elbehi ${ }^{1}$, B Chayeb ${ }^{1}$, W Abbes ${ }^{1}$, F Amorri ${ }^{2}$, Hammami $S^{3}$. ${ }_{1}^{1}$ Psychiatry Department, Regional Hospital, Gabes. Tunisia \\ 2 Outpatients Department, Regional Hospital, Gabes. Tunisia ${ }^{3}$ Internal Medicine Department, Geriatric Unit, CHU Fattouma Bourguiba, Monastir. Tunisia}

Introduction:

In Tunisia, the family is the main source of support for the patient with Alzheimer's disease and plays a key role in his care.

\section{Objective:}

To assess the prevalence of depression among caregivers of Alzheimer's disease patient in the region of Gabes (southern Tunisia).

\section{Patients and methods:}

- A cross-sectional, descriptive study.

- This investigation took place at the psychiatric consultation of the regional hospital of Gabes (South-Eastern Tunisia).

- All caregivers who accompanied their loved ones with Alzheimer's disease to their appointments from November 1, 2016 to January 15, 2017 were invited to take part of the study. Caregivers who were unable to answer questions $(n=4)$ or refused to participate to the study $(n=11)$ were not included.

- We used a questionnaire containing the socio-demographic and medical data of the patient and the caregiver.

- Depression was assessed by the Beck Depression Inventory, validated in Tunisia.

\section{Results:}

- We included 50 caregivers.

- The average age of caregivers was 46 years old. Of those surveyed, $74 \%$ were women, $76 \%$ were married, $84 \%$ was educated and $90 \%$ were unemployed and had a medium to high socio-economic level.

- In $68 \%$ of cases, caregivers lived with patients (68\%).

- Regarding to the care relationship, the mean period of care was 4 years $( \pm 2)$ with an average of 6 hours care per day.

- The mean score of the Beck scale was $8.18( \pm 6.3)$.

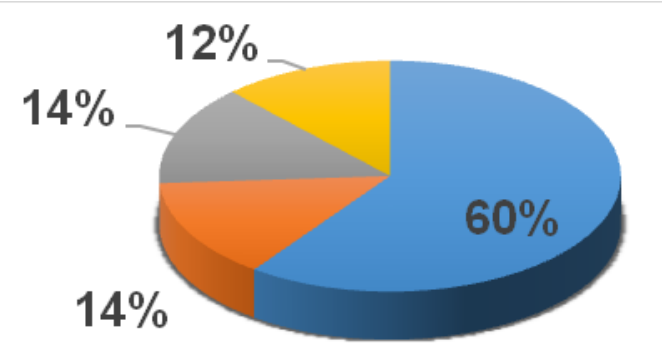

$$
\begin{aligned}
& \text { child } \\
& \text { wife or } \\
& \text { husband } \\
& \text { the daughter }
\end{aligned}
$$$$
\begin{aligned}
& \text { in law } \\
& \text { other }
\end{aligned}
$$

\begin{tabular}{|c|c|c|c|}
\hline & $\begin{array}{c}\text { Not } \\
\text { Depressed } \\
\text { caregiver } \\
\text { Number (\%) }\end{array}$ & $\begin{array}{l}\text { Depressed } \\
\text { caregiver } \\
\text { Number (\%) }\end{array}$ & p \\
\hline $\begin{array}{l}\text { Employment status } \\
\text { Not employed or retired } \\
\text { Liberal profession/Employee }\end{array}$ & $\begin{array}{l}14(50) \\
14(50)\end{array}$ & $\begin{array}{c}19(86) \\
3(14)\end{array}$ & 0,007 \\
\hline $\begin{array}{l}\text { Relationship } \\
\text { Son/ Daughter } \\
\text { Husband/wife } \\
\text { Daughter-in-law } \\
\text { Others }\end{array}$ & $\begin{array}{l}20(72) \\
0(0) \\
4(14) \\
4(14) \\
\end{array}$ & $\begin{array}{l}10(46) \\
7(31) \\
3(14) \\
2(9) \\
\end{array}$ & 0,025 \\
\hline $\begin{array}{l}\text { Residence } \\
\text { With patient } \\
\text { Not with patient }\end{array}$ & $\begin{array}{l}15(53) \\
13(47)\end{array}$ & $\begin{array}{c}19(86) \\
3(14)\end{array}$ & 0,014 \\
\hline
\end{tabular}

Figure 1: Caregiver relationship with patients

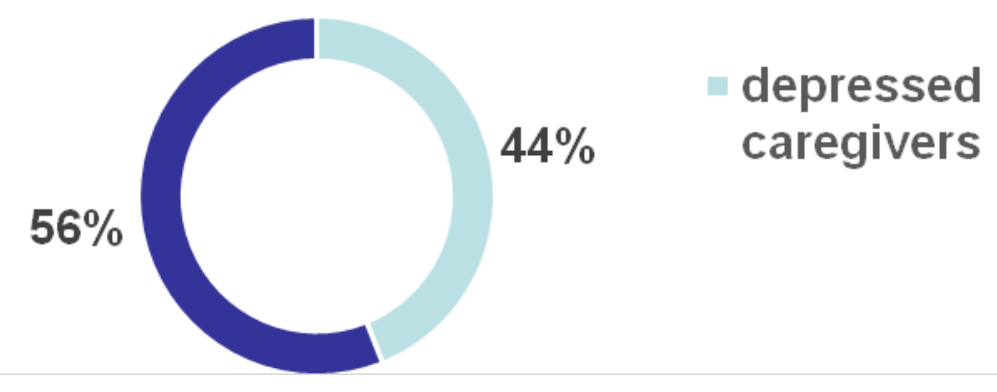

Figure 2: Prevalence of depression among caregivers
Table 1: Correlations of socio-demographic characteristics of caregivers and depression

Discussion:

In our study, caregivers had the following characteristics: an average age of 46 years $( \pm 13$ ), a female predominance (sex ratio $\mathrm{H} / \mathrm{F}$ of 0.35 ), married in $76 \%$. Similar results were observed in a population of 65 caregivers in the Sfax region in 2011 (1).

- Regarding the aid relationship, the average length of assistance was 4 years $( \pm 2)$ with an average duration of assistance of 6 hours / day. Similar results have been reported by other studies $(\mathbf{1 , 2 )}$.

- Among the caregivers in our study, the mean Beck score (8.18 $\pm 6.3)$ was higher than that of the general population $(7 \pm 7.05)$ (3), but lower than that found in another Spanish study (28 \pm 8 ) (4).

- The rate of caregivers in our study who had moderate to severe depression (44\%) was higher than that observed in the Kerhervé study $(\mathbf{1 , 5 )}$. These caregivers were referred to the psychiatric outpatient clinic.

- Caregiver depression was significantly associated with being the husband or the wife of patient and living with him. Several studies on the assessment of the level of burden among caregivers of demented patients are consistent with our findings in concluding that a caregiving and living with caregiver situation was likely a predictor of the burden on caregivers $(5, \mathbf{1}, \mathbf{6})$.

\section{Conclusion:}

Our results reflect the distress of caregivers of Alzheimer's disease patients. Depression is associated to a modifiable factors : lack of work activity for carers and living space shared with the patient. Managing this factors could help caregivers. 